\title{
Molecular and Cytologic Studies of Ehlers-Danlos Syndrome Type VIII
}

\author{
L.G. Biesecker, R.P. Erickson, T.W. Glover, and J. Bonadio \\ Departments of Pediatrics and Communicable Diseases (L.G.B., T.W.G.), Human Genetics (T.W.G.), and Pathology \\ (J.B.), University of Michigan Medical School, and Howard Hughes Medical Institute (J.B.), Ann Arbor, Michigan
}

We present a family with findings of EhlersDanlos syndrome type VIII and a presenile appearance due to decreased subcutaneous tissue with drawn skin, defective wound healing, contractures, and thin hair. To investigate this syndrome, we studied collagen production and the growth properties of cultured fibroblasts taken from affected relatives. We could not find evidence of a collagen defect or premature senescence of cultured fibroblasts, although the fibroblasts may have a decreased growth rate. We conclude that this family has findings of EDS VIII and premature aging and propose that this overlapping phenotype is due to a single pathogenetic mechanism. Our studies of collagen production and fibroblast replication did not discern this mechanism.

KEY WORDS: Ehlers-Danlos syndrome, premature aging, senescence, collagen, periodontitis, skin fragility, autosomal dominant inheritance

\section{INTRODUCTION}

The Ehlers-Danlos syndrome (EDS) eponym includes 15 entries in the current edition of Mendelian Inheritance in Man [McKusick, 1990]. Individuals affected with the various types of EDS have several "cardinal" manifestations including joint hypermobility, skin hyperextensibility, dystrophic scarring, easy bruising, and connective tissue fragility [Beighton et al., 1988]. Ehlers-Danlos syndrome types IV, VI, and VII are associated with abnormal collagen metabolism [Byers et al., 1981; Pinnell et al., 1972; Steinmann et al., 19801. Patients affected with Ehlers-Danlos type VIII have mild

Received for publication July 5, 1990; revision received March 20, 1991.

Address reprint requests to Leslie G. Biesecker, M.D., University of Michigan Department of Pediatrics, Section of Pediatric Genetics, University of Michigan Hospitals, D 1109 M.P.B., Ann Arbor, MI 48109-0718. or no joint hypermobility and skin hyperelasticity, thin skin with easy bruising and defective wound healing especially of the shins and destructive periodontal disease with premature tooth loss [Beighton et al., 1988; Nelson and King, 1981]. One individual with EDS VIII has been reported to have reduced type III collagen [Lapiere and Nusgens, 1981], although a second patient did not demonstrate any abnormality of collagen metabolism [Hartsfield and Kousseff, 1990]. We report on a family with manifestations of EDS VIII and some changes suggestive of "premature aging." Based on the phenotype, we elected to study some of the previously described laboratory findings associated with these disorders in an attempt to characterize this disease.

\section{CLINICAL REPORTS}

The propositus was 36 years old at the time of examination (II-9, Fig. 1). He was diagnosed with Werner syndrome in 1965 . He stated that his skin injures easily and heals slowly. When healing is complete the skin is thin and hyperpigmented. He became edentulous at 16 years because of severe periodontal disease. He smoked approximately one package of cigarettes per day for 2025 years and is an alcoholic. He carried diagnoses of cirrhosis, chronic bronchitis, and pancreatitis. He stated that he underwent a procedure to have his vocal cords "stripped of callouses."

On physical examination his hair was sparse and the scalp veins were prominent (Fig. 2a). His OFC was $52 \mathrm{~cm}(<2$ nd centile). His ears were prominent with simple helices of normal size, the inner canthal distance was $2.6 \mathrm{~cm}$ and the outer canthal distance was $9.4 \mathrm{~cm}$ (both $\sim 3$ rd centile). His eyes, nasal bridge, laryngeal cartilages, and supraclavicular recesses were prominent (Fig. 2b). Anisocoria was present. Decreased breath sounds, ronchi, and dullness to percussion on the left and bibasilar rales were noted on auscultation. A midepigastric mass was present (diagnosed as a pancreatic pseudocyst by his primary physician). A varicocele was present in the left hemiscrotum. His subcutaneous tissue was thin and there were multiple thin, papery scars with patchy hyperpigmentation (Fig. 3), most notable on the shins. He had multiple striae on the abdominal wall as well as an upper transverse abdominal scar which was thin and papery. There were open wounds over the tibiae and mild edema of the feet. Flexion con- 


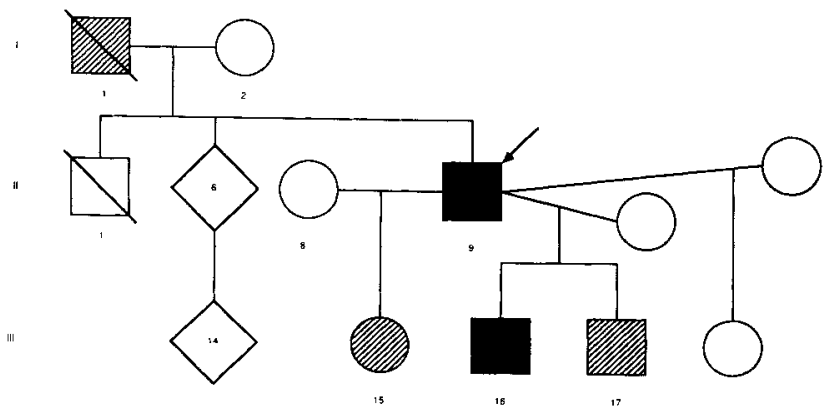

Fig. 1. Pedigree of EDS VIII family. Dark symbols, affected individual by examination; hatched symbols, affected individual by history.
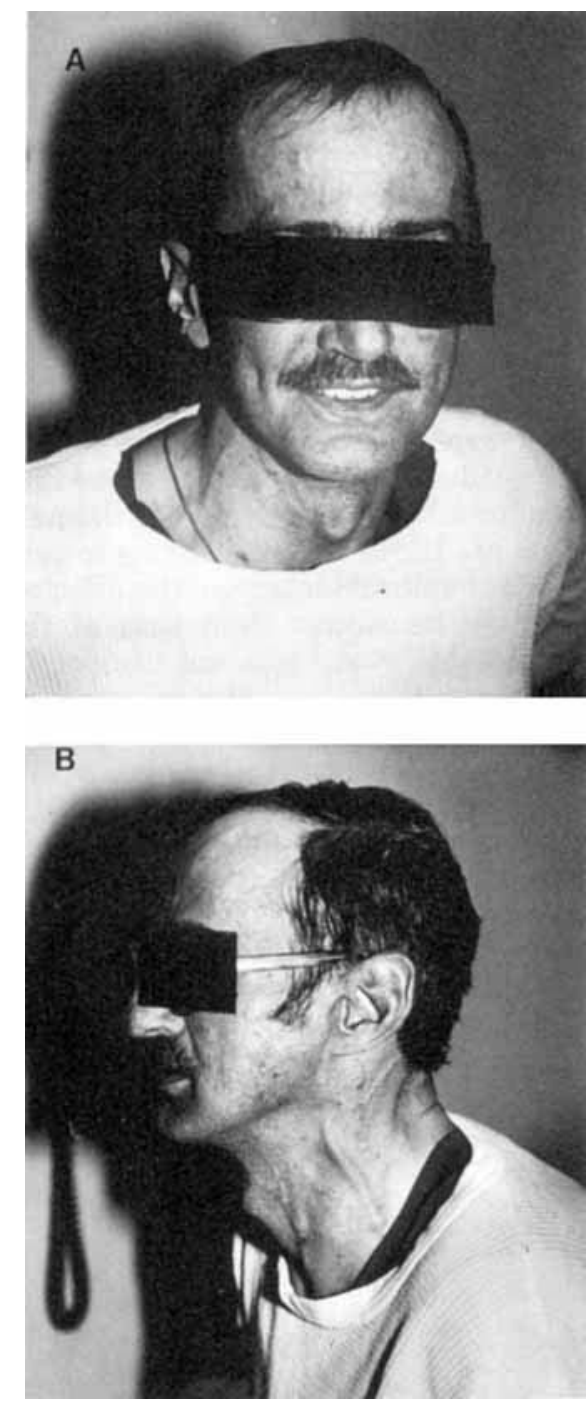

Fig. 2. (a,b) Facial changes of the propositus; note prominent scalp veins, prominent nasal bridge, deep set eyes, and prominent laryngeal cartilage.
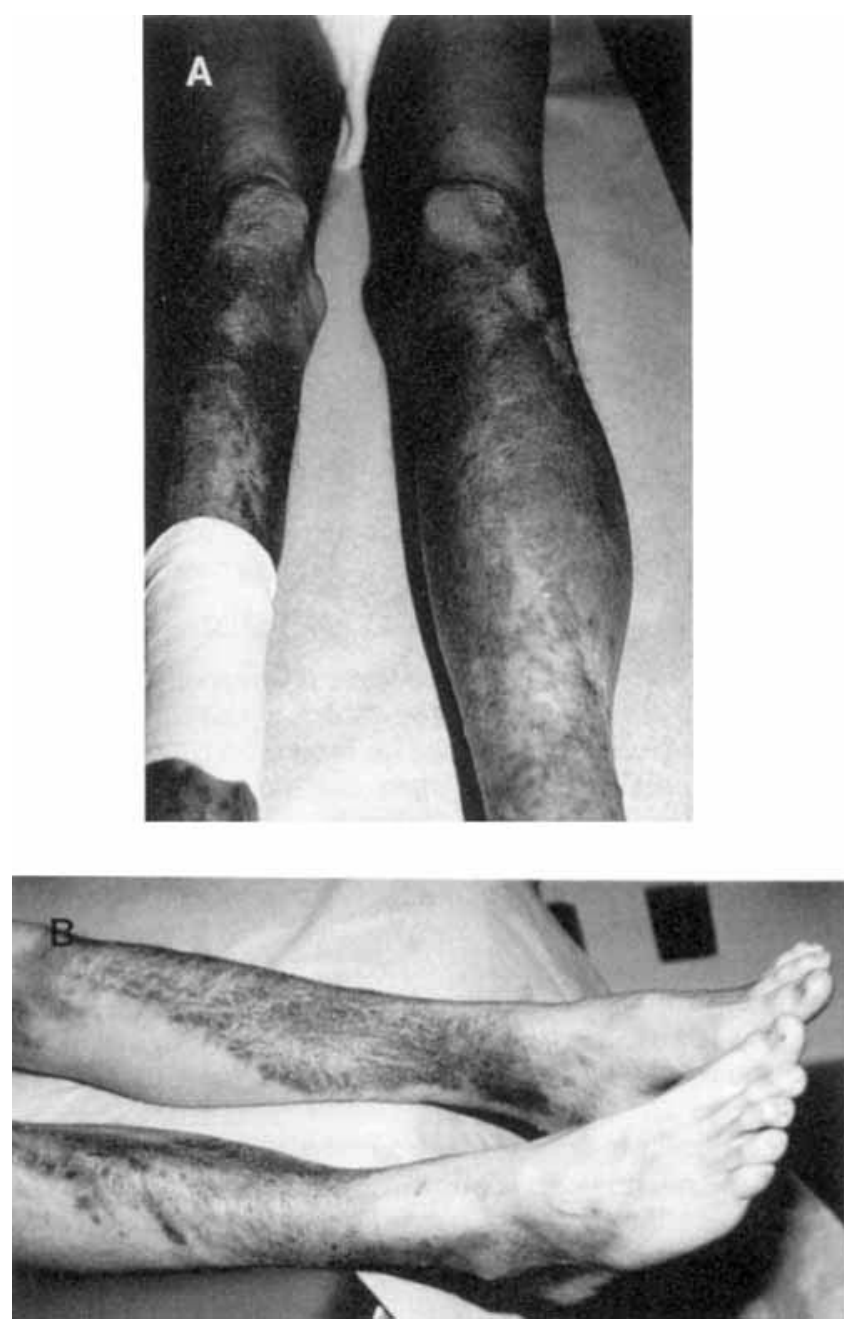

Fig. 3. (a) Legs of propositus; note thin, shiny skin and hyperpigmentation. (b) Legs of affected son of propositus demonstrating similar, but less severe, abnormalities.

tractures of several proximal interphalangeal (PIP) joints, the wrists, and elbows were present.

The 17-year-old son of the propositus (III-16) was also evaluated. His birth and neonatal course were unremarkable. He sustained an injury to his right arm at age 18 months which resulted in dehiscence of the skin. A skin graft was performed at 3 years. Since childhood he complained of easy bruising and frequent nose bleeds. In addition, he had an episode of acute, self-limited, hematuria following a wrestling match. He stated that after any injury his skin became thin, shiny, and hyperpigmented. Myopia was diagnosed at 7 years.

His height was $180 \mathrm{~cm}$, weight was $66 \mathrm{~kg}$, and OFC was $54.75 \mathrm{~cm}$ (all 25th-50th centile). His hair was thin. His facial appearance was remarkable for decreased subcutaneous tissue resulting in sunken cheeks and prominence of the nose, forehead, and laryngeal cartilage. His inner canthal distance was $2.7 \mathrm{~cm}(\sim 3 \mathrm{rd}$ centile) and his outer canthal distance was $9.5 \mathrm{~cm}(\sim 75$ th centile). His teeth were loose and the gingivae were 
erythematous. Several facial telangiectasias were present. His limbs had thin, papery skin with patchy hyperpigmentation. These skin changes were most severe on the anterior tibiae and moderate on the thighs and distal phalanges of the hands. A hematoma was present on the dorsum of one thumb and on the thighs. Striae were present on the thighs. He had bilateral fifth finger clinodactyly, flexion contractures of the PIP joints of both fifth fingers and a short distal phalanx of the second digit of the left hand.

Two other offspring of the propositus were said to be affected with the same disorder but were not available for examination. A son (III-17) was said to be severely affected and a daughter (III-15) was said to be mildly affected. The father of the propositus was also said to be affected but no details were available.

\section{MATERIALS AND METHODS}

Dermal fibroblast cultures were prepared from punch biopsies taken from the inner aspect of the forearm. All biopsies were obtained with the informed consent of the donors. Explanted cells were cultured in Dulbecco's modified Eagle's medium (DMEM) supplemented with $10 \%$ fetal calf serum, penicillin (100 units $/ \mathrm{ml}$ ), and streptomycin $(100 \mu \mathrm{g} / \mathrm{ml})$. All cultures were performed in T-75 $\mathrm{cm}^{2}$ flasks (Corning) at $37^{\circ} \mathrm{C}$ in a humidified atmosphere of air supplemented to $4 \% \mathrm{CO}_{2}$. To investigate the number of cell doublings prior to in vitro senescence, the cultures were grown to near confluence and counted with a hemocytometer and then recultured at a density of $10^{5}$ cells per flask. The cells from the two patients and a normal unrelated control were split into duplicate cultures for a total of 6 cultures.

To study the procollagen, approximately $2.5 \times 10^{5}$ cells were plated into $35-\mathrm{mm}$ dishes and allowed to attach and spread overnight. The next day, cells were preincubated in DMEM supplemented with $50 \mu \mathrm{g} / \mathrm{ml}$ ascorbic acid for $30 \mathrm{~min}$. The medium plus ascorbic acid was replaced and the cells were labeled with L- $\left[2,3,4,5-{ }^{3} \mathrm{H}\right]$ proline (101 $\mathrm{Ci} / \mathrm{mmol}$, Amersham) for $16 \mathrm{hr}$. Following the pulse, medium and cell layer samples were harvested separately in the presence of proteolytic inhibitors and processed for electrophoresis as described [Bonadio et al., 1985]. Procollagen samples were separated on 5\% SDS-PAGE, the gels were dried, and autoradiographs were prepared. A thermal stability study was performed as previously described [Bonadio et al., 1985].

GTG-banded karyotypes were performed by standard methods on cultured fibroblasts from both affected individuals. Karyotyped cells were at approximately the 20th passage.

\section{RESULTS}

Proposed diagnostic criteria for EDS VIII include the cardinal manifestations of EDS in moderate degree (hyperextensible skin, dystrophic scarring, easy bruising, joint hypermobility, and connective tissue fragility) and severe destructive periodontal disease with early tooth loss and gingival recession [Beighton et al., 1988]. The gentlemen reported here manifested dystrophic scarring, easy bruising, tissue fragility, and severe destruc- tive periodontal disease. In addition to the typical EDS VIII findings noted above, the gentlemen reported here also manifested thin, atrophic skin of the face with prominence of scalp veins, eyes, nasal bridge, and neck structures. These findings are seen in some of the "premature aging" syndromes and are also present in the EDS VIII case reported by Stewart et al. [1977]. The patients reported here also have sparse hair which is common in the "premature aging" disorders. The finding of small joint contractures is surprising in a family affected with any type of EDS; however, this finding was also seen in the case of Nelson and King [1981] and is another change seen in some "premature aging" syndromes [Gilkes et al., 1974]. Based on the above considerations we conclude that the family reported here is affected with EDS VIII and, in addition, shows several manifestations that are not common in other EDS VIII patients but are known to occur in the "premature aging" syndromes.

On the basis of this conclusion we studied the replicative potential of fibroblasts in vitro because of the "premature aging" findings. Cells from the two patients grew to more than 25 generations (Fig. 4). Nonquantitative culturing was continued after the formal experimental period for a minimum of 15 generations and showed no evidence of senescence, although one of the samples (RB at day 18-25 and RA at day 25-36) showed a temporary arrest of growth. These cells resumed growth when subcultured and we propose that this arrest was due to a clonal succession as described previously [Salk et al., 1981]. It is interesting to note that the growth rate of the fibroblasts from the affected individuals appears to be slower than that of the control fibroblasts. As this study was not designed to detect such differences with statistical confidence, we are unable to conclude that this effect is real. Chromosomes of fibroblasts from both patients were normal $(46, X Y)$. No increase in chromosome breakage was noted compared to normal control samples (data not shown).

We also studied collagen production because of the EDS-VIII phenotype exhibited by the father and son. In comparison with collagen production by control fibroblasts, no significant differences were observed in the structure, relative rate of secretion, or relative amounts

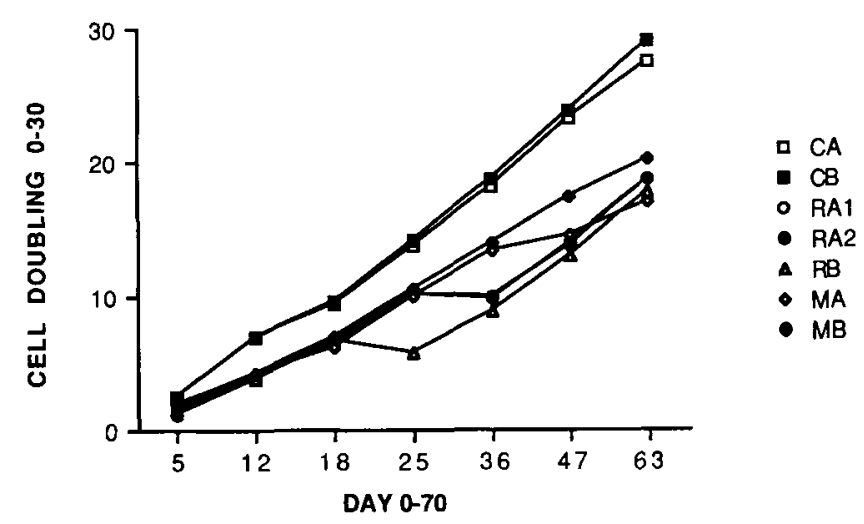

Fig. 4. Fibroblast replication (in doublings) versus time for propositus (RA1, RA2, RB), affected son (MA,MB), and control (CA,CB). 
of fibronectin, type I collagen, or type III collagen produced by either patient's cell line (Fig. 5). In addition, no significant differences were observed in the thermal stability of type I procollagen molecules produced by cells from the propositus, his son, and a control (Fig. 6).

\section{DISCUSSION}

Ehlers-Danlos syndrome type VIII was first described by McKusick [1972] in several relatives of a colleague with defective wound healing, hyperpigmented, atrophic skin and periodontal disease. Full case reports describing an additional 8 patients in 6 families have been published [Stewart et al., 1977; Linch and Acton, 1979; Piette and Douniau, 1980; Nelson and King, 1981; Olesen and Ernst, 1987; Hartsfield and Koussef, 1990]. All pedigrees are compatible with autosomal dominant inheritance. These patients share many of the above noted phenotypic features of EDS VIII and lack (except the case of Piette and Douniau [1980]) the skin hyperextensibility and vascular or viscus rupture typical of other types of EDS. Several additional patients have been reported in abstract form [Hollister et al., 1980; Lapiere and Nusgens, 1981]. The report of Hollister et al. [1980] includes one family of 3 patients whose findings are quite similar to those of the above full case reports and one of these individuals died of duodenal rupture. The second family of at least 4 individuals seems atypical in that they had "only modest skin fragility and bruisability, but moderate to marked skin stretchability." The patient reported by Lapiere

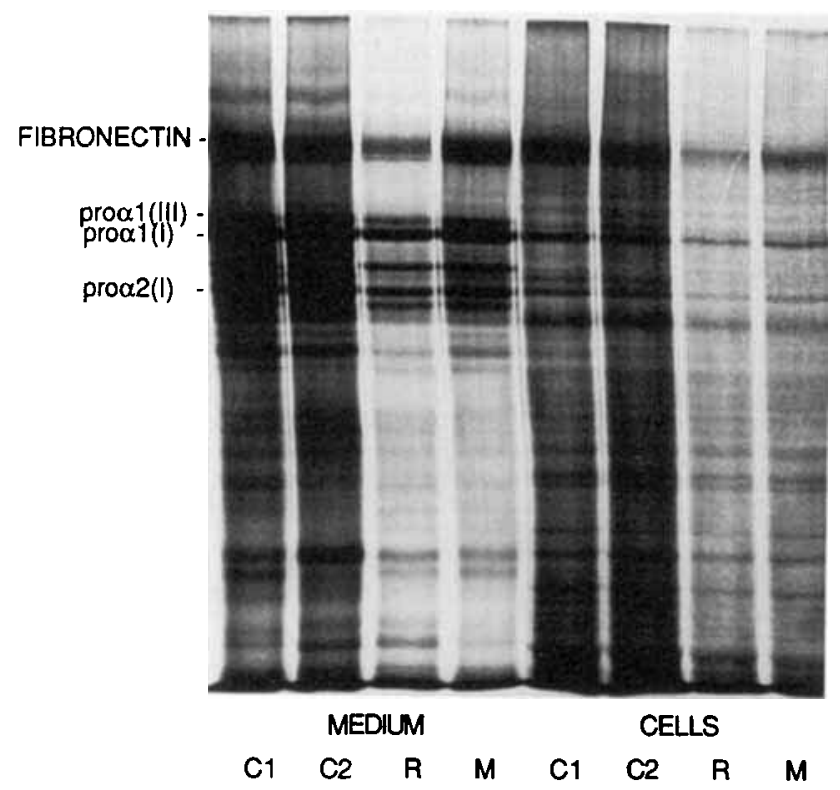

Fig. 5. Matrix macromolecule biosynthesis. Tritiated proline-labeled samples from medium and cell layer compartments of cultured cells derived from controls ( $\mathrm{C} 1$ and $\mathrm{C} 2$, respectively), propositus (R), and son (M) were separated on 5\% SDS-PAGE under reducing conditions, and a radiograph was prepared as described under "Materials and Methods." The production of fibronectin and the constituent chains of collagen types I and III were assessed. Based on a consideration of migration on the gel and secretion efficiency, the synthesis of fibronectin and collagen by cell lines derived from the propositus and his son was considered to be indistinguishable from controls.
A.

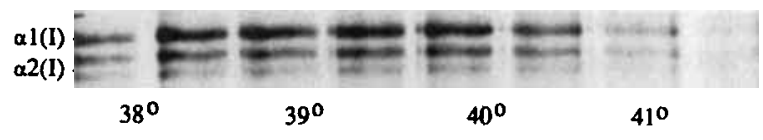

B.

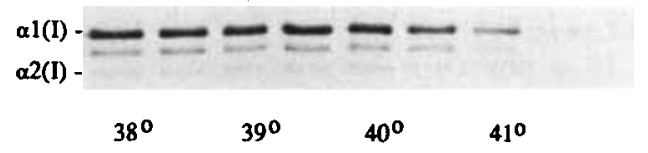

c.

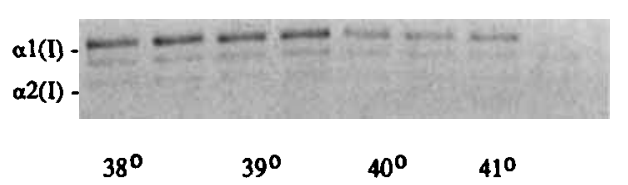

Fig. 6. Thermal stability assay. Equal amounts of radiolabeled, secreted procollagen from a control (A), the propositus (B), and his son (C) were suspended in a neutral salt buffer $(0.01 \mathrm{M}$ Tris, $\mathrm{pH} 7.4,0.4 \mathrm{M}$ $\mathrm{NaCl})$ and warmed over a range of temperatures $\left(38-42^{\circ} \mathrm{C}\right)$ in $0.5^{\circ} \mathrm{C}$ increments. Every $6 \mathrm{~min}$, an aliquot was removed, trypsin $(100 \mathrm{mg} / \mathrm{ml}$, final concentration) was added, and the sample was incubated for $2 \mathrm{~min}$ at $22^{\circ} \mathrm{C}$. At the end of the digest, proteolytic inhibitors and electrophoresis buffer were added, and the sample was boiled for $2 \mathrm{~min}$ and then separated on 5\% SDS-PAGE. Similar to the control, procollagen samples from the propositus and his son were completely digested at $41.5^{\circ} \mathrm{C}$.

and Nusgens [1981] also manifests findings of skin hyperelasticity and fragility, moderate small joint hypermobility, in combination with severe periodontitis. We have also encountered a report by Benjamin and Weiner [1943] which describes a 9-year-old French-Canadian girl with no joint hypermobility or skin hyperextensibility but marked fragility of the skin (most notable on the shins) and periodontal disease.

We are impressed with the overlap of the findings of our patients with both EDS VIII and the "premature aging" syndromes. These syndromes are characterized by a premature appearance of wrinkled, thin skin and skin fragility, decreased subcutaneous tissue, short lifespan, joint contractures, dental loss, short stature, and autosomal recessive inheritance. The fibroblasts of individuals affected with such disorders as Werner syndrome, progeria, and Rothmund-Thomson syndrome demonstrate a significantly reduced potential for in vitro replication when compared to normal controls [Martin et al., 1970; Salk et al., 1981]. The two gentlemen reported here, as well as other patients with EDS VIII, have some manifestations of the "premature aging" disorders. The skin fragility, drawn facial appearance, periodontal disease, and defective healing are findings seen in several of these disorders. However, the finding of attenuated in vitro cell reproduction was not demonstrated in our patients. If a decreased rate of cell 
reproduction were indeed present, as our data suggest, it may be related to the poor wound healing and ulcer formation seen in these patients and may point toward an underlying pathogenetic defect that may be related to the attenuated life span of fibroblasts from individuals with "premature aging" syndromes.

Our studies of collagen production do not rule out all possible derangements of this macromolecule. In particular, we did not see an alteration in the ratio of type I to type III collagen. The abstract published by Lapiere and Nusgens [1981] concludes that the level of type III collagen in a pepsin extract of skin from an EDS VIII patient was reduced compared to control values. The report of Hartsfield and Kousseff [1990] demonstrated normal collagen production and enzymatic stability.

Clearly, this is an emerging syndrome with interfamilial variability and, although diagnostic criteria have been outlined, it is not certain that all of the above families have a single disorder, much less a single mutation. Whether the phenotypic heterogeneity of EDS VIII is due to variable expression or genetic heterogeneity is unanswered.

\section{ACKNOWLEDGMENTS}

The authors wish to thank Dr. Stan Blecher of the University of Guelph, Ontario for translating the Olesen and Ernst article and Dr. Loraine Oman-Gaines for the initial evaluation of these gentlemen.

\section{REFERENCES}

Beighton P, de Paepe A, Danks D, Finidori G, Gedde-Dahl T, Goodman R, Hall JG, Hollister DW, Horton W, McKusick VA, Opitz JM, Pope FM, Pyeritz RE, Rimming DL, Sillence D, Springer JW, Thompson E, Tsipouras P, Viljoen D, Winship I, Young I (1988): International nosology of heritable disorders of connective tissue, Berlin, 1986. Am J Med Gen 29:581-594.

Benjamin B, Weiner H (1943): Syndrome of cutaneous fragility, hyperelasticity and articular hyperlaxity. Am J Dis Child 65:247-257.

Bonadio J, Holbrook KA, Gelinas RE, Jacob J, Byers PH (1985): Altered triple helical structure of type I procollagen in lethal perinatal osteogenesis imperfecta. J Biol Chem 280(3):1734-1742.
Byers PH, Barsh GS, Holbrook KA (1981): Molecular mechanisms of connective tissue abnormalities in Ehlers-Danlos syndrome. Collagen Res 5:475-489.

Gilkes JJH, Sharvill DE, Wells RS (1974): The premature ageing syndromes. Report of eight cases and description of a new entity named metageria. Br J Dermatol 91:243-262.

Hartsfield JK, Kousseff BG (1990): Phenotypic overlap of EhlersDanlos syndrome types IV and VIII. Am J Med Genet 37:465-470.

Hollister DW, Stewart RE, Rimoin DL (1980): Ehlers-Danlos syndrome, type VIII. Clin Res 28:99A (abstract).

Lapiere CM, Nusgens BV (1981): Ehlers-Danlos (ED) type VIII skin has a reduced proportion of collagen type III. J Invest Dermatol 76(5):422 (abstract)

Linch DC, Acton CHC (1979): Ehlers-Danlos syndrome presenting with juvenile destructive periodontitis. Br Dent J 147:95-96.

Martin GM, Sprague CA, Epstein CJ (1970): Replicative life-span of cultivated human cells. Effects of donor's age, tissue and genotype. Lab Invest 23(1):86-92.

McKusick VA (1972): "Heritable Disorders of Connective Tissue," 4th ed. St. Louis: CV Mosby, pp 292-371.

McKusick VA (1990): "Mendelian Inheritance in Man," 9th ed. Baltimore: Johns Hopkins University Press.

Nelson DL, King RA (1981): Ehlers-Danlos syndrome type VIII. J Am Acad Dermatol 5(3):297-303.

Olesen BH, Ernst E (1987): Orale manifestationer ved Ehlers-Danlos syndrom type VIII. Tandlaegebladet 91:313-315.

Piette E, Douniau R (1980): Parodontolyse infantile symptomatique d'un syndrome D'Ehlers-Danlos, un case sporadique? Acta Stom Belg 77:217-229.

Pinnell SR, Krane SM, Kenzora JE, Glimcher MJ (1972): A heritable disorder of connective tissue. Hydroxylysine-deficient collagen disease. N Engl J Med 286:1013-1020.

Salk D, Au K, Hoehn H, Stenchever MR, Martin GM (1981): Evidence of clonal attenuation, clonal succession and clonal expansion in mass cultures of aging Werner's syndrome fibroblasts. Cytogenet Cell Genet 30:108-117.

Steinmann B, Tuderman L, Peltonen L, Martin GR, McKusick, Prockop DJ (1980): Evidence for a structural mutation of procollagen type I in a patient with the Ehlers-Danlos syndrome type VII. J Biol Chem 255:8887-8893.

Stewart RE, Hollister DW, Rimoin DL (1977): A new variant of EhlersDanlos syndrome: An autosomal dominant disorder of fragile skin, abnormal scarring, and generalized periodontitis. In Bergsma D, Lowry RB (eds): "New Syndromes." New York: Alan R. Liss, for the National Foundation-March of Dimes. BD:OAS XIII(3B):85-93. 